\title{
Profesor Dr. Yves Keravel
}

El obituario oficial del Prof. Dr. Yves Keravel nos dirá que fue Jefe de Servicio de Neurocirugía en el Hospital Henri Mondor entre 1989 y 2010, que fue miembro fundador de la IASP en 1975, que fue Presidente de la Sociedad Francesa de Neurocirugía y de la Sociedad de Neurocirugía de Habla Francesa. Coordinador de los comités de la WFNS desde 2009, miembro honorario de la misma WFNS, autor de más de 200 publicaciones y monografías además de más de 90 conferencias en el extranjero por invitación. Nos dirá finalmente que falleció repentinamente el 3 de diciembre 2015 luego de una relativamente corta enfermedad. Lo que ese obituario no relata fue su relación extensa, fructífera y cercana con la Neurocirugía chilena que nació - y aquí, desafortunadamente, hay que ser autoreferente - en octubre de 1977 cuando quien escribe llegó al Servicio de Neurocirugía del Hospital Henri Mondor, dirigido en ese entonces por el Prof. J.P. Caron para iniciar su residencia extranjera. Ahí trabó conocimiento con el también recién llegado Dr. Keravel. Afinidades personales y de edad hicieron nacer una amistad que se consolidó durante 1978 y que continuó luego del retorno a Santiago para culminar en la realización de las primeras Jornadas Franco-Chilenas de Neurocirugía en 1980 con su presencia como conferencista. Las Jornadas continuaron en forma más o menos regular durante varios años contando siempre con su presencia y acompañado cada vez por algún otro colega francés que el se encargaba de reclutar para tales efectos. Si bien las Jornadas fueron importantes para la Neurocirugía chilena, su aporte más significativo fue su compromiso no escrito de reservar una plaza anual en el Servicio para un residente extranjero chileno, lo que permitió durante varios años la estadía de numerosos colegas chilenos que pudieron completar su formación y empaparse de la rica tradición neuroquirúrgica francesa de la cual el Dr. Keravel era su heredero y continuador. Esto lo hizo merecedor de su nombramiento como Miembro correspondiente de nuestra Sociedad en 1999 y luego Miembro Honorario en 2008. Entre sus cualidades personales habría que mencionar su impresionante capacidad de trabajo, su rigurosidad como docente y su notable habilidad quirúrgica. Quienes tuvimos el privilegio de conocerlo de cerca podemos además mencionar su invariable buen humor, su capacidad para sentirse a gusto en cualquier lugar y su afición por el turismo de aventura que nos permitió inolvidables viajes por Chile, cuyo paisaje le pareció siempre extremadamente bello. Mención aparte merece Francoise, su esposa, cuya hospitalidad generosa permitió que varios de nosotros fueran acogidos en su casa por períodos a veces prolongados. Vayan para ella nuestras simpa-

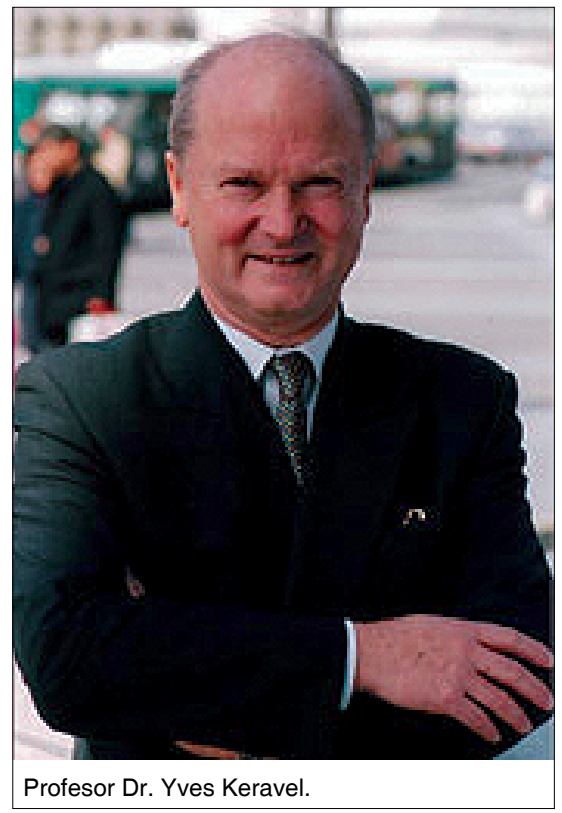

tías y condolencias más sinceras. Con estas cortas palabras la Sociedad de Neurocirugía de Chile quiere rendirle un homenaje póstumo a un amigo incondicional que tanto aportó al desarrollo de nuestra especialidad. Sus amigos chilenos lamentamos su inesperada partida y hacemos votos para que su alma descanse en paz.

Dr. Enrique Colin B, $\mathrm{MSNcCh}$ 